\title{
Pembentukan Karakter Kepemimpinan Pemuda Melalui Wadah Pembinaan Dewan Kerja Pramuka Penegak dan Pramuka Pandega di Kwartir Cabang Kudus
}

\author{
Misroh Sulaswari $^{\text {a, } 1}$, Muhammad Nurul Yaqin ${ }^{\text {b, } 2}$, Muhammad Hafidz ${ }^{\text {b, } 3}$ \\ ${ }^{\text {a }}$ IAIN Kudus, misrohsulaswari@iainkudus.ac.id \\ ${ }^{\mathrm{b}}$ IAIN Kudus, yaqinfilan152103@gmail.com

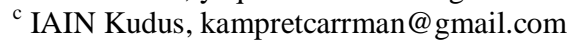

\begin{tabular}{ll}
\hline & ABSTRAK \\
\hline Kata kunci: & Pendidikan Karakter menjadi sebuah jalan keluar bagi proses pembinaan pramuka \\
Pendidikan & penegak dan pramuka pandega dalam menginternalisasikan nilai-nilai \\
Karakter & kepemimpinan bagi para anggota pramuka. Penelitian ini bertujuan untuk \\
Pramuka & mmendeskripsikan bagaimana gerakan pramuka menumbuhkan karakter \\
Kepemimpinan & kepemimpinan bagi bagi anggota pramuka. Penelitian ini dilaksanakan dengan \\
& menggunakan pendekatan kualitatif deskriptif. Hasil penelitian menunjukkan \\
& bahwa nilai karakter kepemimpinan Dewan Kerja Cabang Kudus dapat dilihat dari \\
& strategi koordinasi kepada para anggota Pramuka Penegak dan Pramuka Pandega se \\
& Kwartir Cabang Kudus. Selain itu, seni komunikasi yang demokratis dan rasa \\
& tanggungjawab yang tinggi dalam memimpin Pramuka Penegak dan Pramuka \\
& Pandega se Kwartir Cabang Kudus menjadikan para anggota pramuka semakin \\
& solid dan mempunyai prinsip kerja ikhlas dan tuntas.
\end{tabular}

\section{ABSTRACT}

Keyword:

Character Education is a way out for the process of fostering scout enforcement and Education pandega scouts in internalizing leadership values for scout members. This study aims to Characters Scouts Leadership describe how the scout movement fosters leadership character for scout members. This research was conducted using a descriptive qualitative approach. The results showed that the leadership character value of the Kudus Branch Work Council can be seen from the coordination strategy to the members of the Scout Enforcement and Pandega Scouts throughout the Kudus Branch Council. In addition, the art of democratic communication and a high sense of responsibility in leading the Scout Enforcement and Pandega Scouts in the Holy Branch has made scout members more solid and have sincere and thorough working principles.

Copyright $\odot 2020$ Tadris IPS Institut Agama Islam Negeri Kudus. All RightReserved

\section{Pendahuluan}

Pendidikan adalah usaha sadar dan terencana untuk mewujudkan suasana belajar dan proses pembelajaran agar peserta didik secara aktif mengembangkan potensi dirinya untuk memiliki kekuatan spiritual keagamaan, pengendalian diri, kepribadian, kecerdasan, akhlak mulia, serta ketrampilan yang diperlukan dirinya, masyarakat, bangsa dan negara. Nasional mendedikasikan ranah pendidikan harapannya berdasarkan pancasila dan Undang-undang Dasar Negara Republik Indonesia 1945 yang berakar pada nilai-nilai agama, kebudayaan nasional Indonesia dan tanggap terhadap tuntutan perubahan zaman (Chomaidi dan Salamah, 2018:129). Dengan demikian pendidikan sejatinya harus 
mengarahkan pada sebuah perubahan yang baik dan signifikan.

Pendidikan Indonesia masih mengedepankan adanya kegiatan pendidikan yang formal. Hal ini dapat ditinjau dari banyaknya sekolah formal di Indonesia tercatat 281.668 sekolah ("Daftar Sekolah Dasar di Indonesia",https://id.wikipedia.org/wiki/Daftar_ sekolah_dasar_negeri_di_Indonesia, akses tanggal 17 Februari 2020). Penerapan pendidikan formal yang masih terikat pada sistem masing-masing sekolahan dan berbentuk indoor-class mengakibatkan kurangnya penggalian potensi peserta didik dalam ranah aktif mengembangkan potensi diri. Maka dari itu, pendidikan formal masih perlu pendampingan pendidikan non-formal yang masuk pada kegiatan ekstrakulikuler sekolah.

Chomaidi dan Salamah (2018:130), dalam bukunya menuliskan bahwa pelaksanaan pendidikan di Indonesia memang memiliki 3 jalur yaitu pendidikan formal, nonformal dan informal. Pendidikan formal adalah jalur pendidikan yang terstruktur dan berjenjang yang terdiri atas pendidikan dasar, pendidikan menengah dan pendidikan tinggi. Selanjutnya, pendidikan nonformal adalah jalur pendidikan di luar pendidikan formal yang dapat dilaksanakan secara terstruktur dan berjenjang. Sedangkan pendidikan informal adalah jalur pendidikan keluarga dan lingkungan.

Pemaparan di atas menunjukan bahwa kegiatan ekstrakulikuler masuk pada pendidikan nonformal. Penulis mengangkat pendidikan nonformal Gerakan Pramuka yang digadang-gadang sebagai garda terdepan bangsa untuk membentuk karakter pemuda. UU No 12 Tahun 2010 menjelaskan Gerakan Pramuka adalah organisasi yang dibentuk oleh pramuka untuk menyelenggarakan pendidikan kepramukaan. Pendidikan Kepramukaan adalah proses pembentukan kepribadian, kecakapan hidup, dan akhlak mulia pramuka melalui penghayatan dan pengamalan nilai-nilai kepramukaan.

Dewasa ini, permasalahan remaja semakin kompleks mulai dari degradasi moral kaum muda, menurunnya semangat patriotisme dan nasionalisme kaum muda dan meningkatnya penyalah gunaan narkoba serta miras di kalangan kaum muda (SK 176 : 2013). Masalah di atas menjadi sebuah polemik negara yang sangat perlu mendapatkan perhatian secara penuh. Gerakan pramuka dalam hal ini sebuah organisasi yang bergerak dibidang pendidikan dan kepemudaan mengambil andil dalam penyelesaian tersebut. Kenakalan remaja tersebut mulai muncul pada usia-usia golongan Penegak dan Pandega antara Usia 16-25 tahun. Oleh karenanya, hadirnya gerakan pramuka adalah sebagai wadah pembinaan kaum muda untuk mengentaskan problema di atas serta meningkatkan karakter pemuda yang nantinya akan menjadi penerus estafet kepemimpinan bangsa Indonesia.

Hal ini semakin kuat dengan pemberlakuan peraturan menteri pendidikan dan kebudayaan Republik Indonesia no 63 tahun 2014 tentang Pendidikan Kepramukaan sebagai kegiatan Ekstrakulikuler wajib pada pendidikan dasar dan pendidikan menengah. Dalam peraturan menteri pendidikan dan kebudayaan Republik Indonesia no 63 tahun 2014 menjelaskan pada pasal 3: (1) Pendidikan Kepramukaan dilaksanakan dalam 3 (tiga) model meliputi model blok, model aktualisasi, dan model reguler, (2) Model blok sebagaimana dimaksud pada ayat (1) merupakan kegiatan wajib dalam bentuk perkemahan yang dilaksanakan setahun sekali dan diberikan penilaian umum. (3) Model aktualisasi sebagaimana dimaksud pada pasal (1) merupakan kegiatan wajib dalam bentuk penerapan sikap dan ketrampilan yang dipelajari di dalam kelas yang dilaksanakan dalam kegiatan kepramukaan secara rutin, terjadwal, dan diberikan penilaian formal, (4) Model reguler sebagai dimaksud pada ayat (1) merupakan kegiatan sukarela berbasis minat peserta didik yang dilaksanakan di Gugus Depan. Dengan demikian, Gerakan Pramuka telah menjadi organisasi pemuda yang dipilih dan dipercaya oleh pemerintah dalam pengembangan kepemudaan, menunjukan kualitas atas pendidikan yang dilaksanakan pada peserta didik di kepramukaan. 
Hadir dengan wujud wahana dan wadah pengembangan kepemudaan, dalam Gerakan pramuka anggota muda digolongan menjadi 4 , yaitu Siaga, Penggalang, Penegak dan Pandega. Pada taraf golongan Siaga dan Penggalang sistem pembinaannya masih terpusat pada Anggota Dewasa atau orangtua sedangkan pada golongan Penegak Pandega (usia 16-25 tahun) sistem pembinaan telah menerapkan prinsip kegiatan dari, oleh dan untuk Pramuka Penegak dan Pandega. Jadi, pada usia inilah anak usia tersebut diajarkan bagaimana mengelola sebuah organisasi dan kegiatan secara mandiri.

Bentuk stimulus untuk memperkuat usia penegak dan pandega, Gerakan Pramuka memberikan wadah pembinaan yang dinamakan Dewan Kerja. Dewan Kerja merupakan sebuah wadah yang berada di Kwartir yang dipercaya untuk mengelola secara langsung Penegak dan Pandega di wilayahnya. Kwartir Cabang Kudus terdapat Dewan Kerja Cabang Kudus yang beranggotan Penegak dan Pandega di wilayah Kabupaten Kudus. Anggota tergabung melalui Seleksi dari 9.858 Penegak dan Pandega di Kudus. Komposisi Dewan Kerja Cabang Kudus maksimal 21 orang sesuai SK Kwarnas Nomor 005 tahun 2017. Dengan prinsip kegiatan Dari, Oleh dan Untuk Pramuka Penegak dan Pandega, diusia tersebut anggota Dewan Kerja Cabang diamanati oleh Kwartir Cabang Kudus untuk mengelola 9.858 dalam hal Pembinaan dan Fasilitasi Kegiatan yang sesuai dengan golongan Penegak dan Pandega. Melalui proses kemandirian, learning by doing dan managament risiko disetiap prosesnya telah terbukti dapat menumbuhkan pendewasaan dan karakter kepemimpinan bangsa yang ideal. Hal ini semakin didukung dengan tagline Gerakan Pramuka yaitu Ikhlas Bakti Bina Bangsa, dimana anggota Dewan Kerja Cabang tidak menerapkan sistem benefit profit disetiap prosesnya. Penuturan dari Ketua DKC Kudus kak Muhammad Nurul Yaqin ketika ada permohonan pemateri maka prinsip yang diterapkan tidak pernah menerima dukungan finansial dari pihak pemohon. Hal ini merupakan bentuk pendewasaan seorang pemimpin di mana banyak alasan dan latar belakang dicetuskannya prinsip bahwa semua penegak dan pandega di satuan/gudep/sekolahan memiliki finansial yang memadai sehingga dengan diundangnya DKC Kudus untuk mengisi materi itu sudah sangat baik karena DKC Kudus memiliki prinsip dapat turun kebawah secara tersirat dan mengetahui kondisi penegak dan pandega secara baik. Kebiasaan tersebut yang menjadikan karakter kepemimpinan di Dewan Kerja Cabang Kudus.

Penulis pada rencana penelitian ini akan memaparkan bagaimana gerakan pramuka menumbuhkan karakter pemuda bangsa serta wujud dari kegiatan pramuka yang telah dilaksanakan dapat mencapai karakter kepemimpinan secara maksimal. Judul penelitian ini adalah Pembentukan Karakter Kepemimpinan Pemuda melalui Wadah Pembinaan Dewan Kerja Pramuka Penegak dan Pramuka Pandega di Kwartir Cabang Kudus.

\section{Metode}

Metode dan pendekatan yang digunakan dengan menggunakan teknik pengamatan dan Praktik terhadap obyek secara langsung yaitu kegiatan dan pemuda. Penelitian ini merujuk pada metode kualitatif di mana penelitian ini bersifat deskriptif analisis. Data kualitatif ini diperoleh dari berbagai macam teknik pengumpulan data yaitu observasi, wawancara dan dokumentasi. Teknik analisis pada penelitian ini adalah analisis naratif yaitu memahami identitas dan pandangan terhadap Dewan Kerja Cabang Kudus mengacu pada cerita-cerita (naratif) dan penuturan aktivitas kesehariannya. Subjek penelitian ini adalah anggota Dewan Kerja Pramuka Penegak dan Pramuka Pandega Kwartir Cabang Kudus (DKC Kudus).

\section{Hasil dan pembahasan}

\section{Pola Mekanisme Pembinaan Pramuka Penegak dan Pramuka Pandega}

Gerakan Pramuka Indonesia adalah nama organisasi pendidikan nonformal yang menyelenggarakan pendidikan kepanduan yang dilaksanakan di Indonesia. 
Kata Pramuka merupakan singkatan dari Praja Muda Karana, yang berarti rakyat muda yang suka berkarya. Teori ini nanti yang kan dijadikan penulis sebagai landasan teori penlitian ini (M. Sumanta dan Fitri Juwita Santi' 2014: 1).

Kegiatan pendidikan kepramukaan dilaksanakan dengan menggunakan sistem among. Sistem among merupakan proses pendidikan kepramukaan yang membentuk peserta didik agar berjiwa merdeka, disiplin dan mandiri dalam hubungan timbal balik antarmanusia. Sistem among tersebut dilaksnakan dengan menerapkan prinsip kepemimpinan,

a. Di depan sebagai teladan

b. Di tengah membangun kemauan

c. Di belakang mendorong serta memberikan motivasi kemandirian.

Pendidikan kepramukaan dalam sistem pendidikan nasional termasuk dalam jalur pendidikan nonformal yang diperkarya dengan pendidikan nilai-nilai gerakan pramuka dalam pembentukan kepribadian yang berakhlak mulia, berjiwa patriotik, taat hukum, disiplin, menjunjung tinggi nilai-nilai luhur bangsa dan memiliki kecakapan hidup. Jenjang pendidikan kepramukaan terdiri atas jenjang pendidikan (UU No 12 Tahun 2010):
a. Siaga
b. Penggalang
c. Penegak
d. Pandega

Pramuka siaga merupakan golongan pramuka tingkat dasar yang digolongkan sesuai usia yaitu 7-10 tahun. Selanjutnya, penggalang adalah golongan pramuka di atas siaga yang berumur 11-15 tahun. Golongan berikutnya adalah Penegak yang masuk pada golongan ini adalah usia 16- 20 tahun. Terakhir dalam usia peserta didik adalah golongan pandega usia mulai 21-25 tahun. Selain peserta didik dalam pramuka terdapat Pembina pramuka, Andalan, Pelatih, Pamong Saka, Majlis Pembimbing dan Staf Kwartir.
Hasil kajian penggolongan pramuka diatas, focus penelitian ini adalah golongan penegak pandega sebagai obyek kajian pembentukan karakter di Dewan Kerja Pramuka Penegak dan Pandega. Proses pembinaan Pramuka Penegak dan Pramuka terdapat Surat Keputusan Nomor 176 Tahun 2013 tentang Pola Mekanisme Pembinaan Pramuka Penegak dan Pramuka Pandega. Tujuan Pola Mekanisme Pembinaan Pramuka Penegak dan Pandega adalah untuk digunakan sebagai pedoman dalam menyelenggarakan pembinaan bagi Pramuka penegak dan Pandega dengan Sistematis dan Terarah dan Menyelaraskan pelaksanaan pembinaan pramuka penegak dan Pandega.

Adapun sasaran pembinaan pramuka penegak diarahkan kepada peningkatan kualitas yang mampu:

a. Menjalankan tugas Agamanya secara teratur

b. Mengungkapkan rasa syukur kepada Tuhan Yang Maha Esa dengan meningkatkan iman dan dedikasinya

c. Hormati keyakinan agama orang lain

d. Hormati pendapat orang lain

e. Berkolaborasi dan berinteraksi dengan orang lain dalam group

f. Mengikuti aturan group dan terima konsekuensinya

g. Peduli terhadap orang lain dan lingkungannya

h. Kumpukkan dan proses informasi yang diperlukan untuk menyelesaikan keputusan dari sebuah masalah

i. Berinovasi dan berkreasi di bidang sains dan teknologi, serta melakukan ekplorasi ketrampilan pramuka

j. Menerapkan ilmu yang dimilikinya

k. Menjaga dan memelihara kesehatan tubuh melalui olahraga

1. Menggunakan kemampuan fisiknya

m. Menggambarkan perkembangan fisik dan mental manusia

Pemaparan di atas telah menjelaskan bagaimana gerakan pramuka dalam melaksanakan sebuah kehidupan organisasi. 
Dengan banyaknya landasan teori dan materi yang disesuaikan dengan kondisi manusianya misalnya penggolongan sesuai umur dan adanya sasaran yang pasti sebagai tolok ukur capaian pembinaan merupakan bentuk kegiatan organisasi yang terarah. Pada perspektif yuridis, gerakan pramuka sangatlah kuat dengan adanya konsensus yang melandasi. Oleh karena itu adanya konsesus sebuah organisasi akan sampai pada pemerintah negara yang aman dan terlindungi dari perpecahan.

Upaya gerakan pramuka dalam mencapai sasaran pembinaan di atas, termakstub dalam Surat Keputusan Nomor 176 tahun 2013 tentang Pola Mekanisme Pembinan Pramuka Penegak dan Pramuka Pandega yaitu melalui Prinsip pembinaan, Wadah Pembinaan serta Kegiatan. Prinsip Pembinaan pramuka penegak dan pandega adalah untuk mempersiapkan diri sebagai pemimpin yang bertanggung jawab kepada diri sendiri, keluarga, masyarakat, bangsa, negara dan Tuhan Yang Maha Esa, melalui tri bina yaitu: bina diri, bina satuan dan bina masyarakat.

Bina diri adalah kegiatan meningkatkan pengetahun dan ketrampilan. Bina satuan dalah mempersiapkan diri menjadi instruktur dalam ketrampilan kepramukaan tertentu pada perindukan siaga dan pasukan penggalang. Bina masyarakat adalah mempersiapkan diri menjadi pemimpin di masyarakat. Tri bina inilah yang menjadi prinsip pembinaan pramuka penegak dan pandge dimana arah kiprahnya adalah menuju kebermanfaatan kepada masyarakat. Hal ini sangat sinkorn jika dikaitkan dengan Tri Darma Perguruan Tinggi yang terdiri atas Pendidikan, Penelitian dan Pengabdian Masyarakat. Tri Bina dan Tri Darma memiliki arah yang sama yaitu menuju pada kebermanfaatan masyarakat. Jadi, gerakan pramuka sangatlah relevan dengan keadaan yang ada dan dibutuhkan oleh masyakarat.

Selain prinsip pembinaan dalam proses pola dan mekanisme pembinaan pramuka penegak dan pandega adanya sebuah wadah pembinaan yang menjadi tempat anggota pramuka penegak dan pandega berlatih. Wadah pembinaan menjadi sangat penting karena merupakan wahana berdinamika dalam upaya membentuk kebiasaan untuk menjadi pribadi yang berkarakter sesuai harapan masyarakat. Wadah pembinaan pramuka penegak dan pramuka pandega sebagai berikut :

a. Wadah pembinaan gugus depan

Merupakan wadah pembinaan bagi pramuka penegak dan pandega yang nomor 1. Gugus depan merupakan pusatnya peserta didik dilahirkan dan didik untuk menarima dan pengetahun serta pembentukan karakter muda yang baik.

b. Wadah pembinaan di satuan karya pramuka

Satuan karya pramuka (SAKA) (SK KN No 170. A Tahun 2008) adalah forum pendidikan dan pendampingan untuk menyebarkan minat, mengembangkan bakat dan menambah pengalaman para pramuka usia $16-25$ tahun dalam berbagai bidang ilmu pengetahuan dan teknologi serta ketrampilan. Saka juga mendorong mereka untuk melakukan kegiatan yang praktis dan bermanfaat untuk memberikan mereka keamanan mata pencaharian sekaligus memberikan pelayanan kepada masyarakat, negara sesuai dengan keinginan pemuda Indonesia dan kebutuhan untuk pembangunan dan peningkatan ketahanan nasional. Jadi, Saka merupakan Forum pendidikan untuk minat bakat yang diinginkan oleh peserta didik. Saka secara nasional terdapat 11 saka, yaitu Saka Taruna Bumi, Wirakartika, Bhayangkara, Bahari, Dirgantara, Kencana, Bakti Husada, Wanabakti, Pariwisata, Kalpataru, dan Widya Budaya Bakti. 
c. Wadah pembinaan di kwartir

Dewan Kerja Pramuka Penegak dan Pandega adalah Organisasi untuk membimbing dan pembaharuan kepemimpinan di tingkat kwartir. Dewan Kerja Pramuka Penegak dan Pandega beranggotakan pramuka usia 16- 25 tahun yang dipilih dalam Forum Musyawarah yaitu Musppanitra bersifat kolektif dan kolegial yang merupakan bagian integral dari kwartir, berkedudukan sebagai bidang kelengkapan kwartir yang diberi kekuasaan dan kepercayaan untuk mengelola kegiatan pramuka usia 1625 tahun.

Selanjutnya adalah kegiatan yang menunjang terjadinya dinamika dan menuju pendewasaan peserta didik. Gerakan pramuka memberi kesempatan kepada pramuka usia 16-25 tahun untuk merencanakan, melaksanakan, dan mengevaluasi kegiatan pramuka penegak pandega. Adapun prinsip-prinsip kegiatan pramuka penegak dan pandega adalah sebagai berikut:

a. Dari, oleh, dan untuk pramuka penegak pandega, dengan mitra pembina.

b. Karakteristik, dinamika, giat, menantang, bermanfaat bagi diri sendiri dan masyarakat, serta berpegang pada 5 bidang pengembangan diri (spiritual, emosional, sosial, intelektual, dan fisik).

c. Membangkitkan, mendorong, dan mengarahkan serta mengatur dan mengembangkan keinginan/minat, semangat serta keterampilan dan jiwa wirausaha pramuka penegak dan pandega.

\section{Pembentukan Karakter Kepemimpinan Pramuka Penegak dan Pandega}

Paparan tentang pola mekanisme dan pembinaan pramuka penegak dan pandega telah menjelaskan bahwa proses pendidikan pada tingkatan golongan penegak adalah bersifat mandiri, akan tetapi masih adanya sebuah mitra pembinaan yaitu seorang pembina sebagai konsultan. Hal ini termaktub dalam surat keputusan nomor 176 tahun 2013 tentang pola mekanisme pembinaan pramuka penegak dan pandega yaitu pada Bab 3 Pembinaan Sub bab 4 pelaksanaan pembinaan yaitu:

a. Pembinaan di gugus depan dilaksanakan oleh pembina yang bertindak sebagai instruktur, konsultan, motivator dan performer ambalan penegak.

b. Pembinaan di Saka dilaksanakan oleh pamong saka yang bertindak sebagai instruktur, konsultan, motivator dan performer satuan karya pramuka.

c. Pembinaan di kwartir dilaksanakan oleh pimpinan kwartir yang berfungsi sebagai mentor, konsultan, narasumber, pendukung sarana dan prasarana acara, motivator dan konsultan Dewan Kerja Pramuka Penegak dan Pandega.

Pembentukan karakter pramuka penegak dan pramuka pandega adalah melalui pembinaan dan kegiatan yang dilaksanakan. Sistem yang dipaparkan di atas telah menjelaskan bagaimana penegak dan pandega berproses. Prinsip kegiatan yang mencakup 5 bidang pengembangan diri mulai dari spiritual, emosional, sosial, intelektual dan fisik telah menghantar pramuka penegak dan pandega kepada masa depan yang mumpuni. Pada proses pendidikan peserta didik melakukan kegiatan ranahnya adalah untuk pendewasaan, sehingga peserta didik dapat mengilhaminya.

Setiap kegiatan pramuka menjadi miniatur masyarakat majemuk yang ada. Adanya bina diri, bina satuan dan bina masyarakat adalah untuk membekali peserta dalam menghadapai setiap bentuk dinamika di masyarakat. Mulai dari bina diri, harapannya peserta didik dapat mengetahui tentang proses penjagaan diri terutama bersikap sesuai dengan yang diinginkan oleh masyarakat. Masyarakat 
adalah penonton dan kita adalah pemeran di atas panggung, bagaimana bina diri ini adalah solusi terhadap permasalahan tersebut.

Hal tersebut masuk dalam teori sosial yaitu Teori Dramaturgi. Teori ini dikembangkan oleh tokoh yang bernama Ervin Goffmen. Teori ini meyakini bahwa kehidupan adalah panggung pentas dimana masyarakat adalah penonton dan Tuhan Yang Maha Esa adalah sutradara handal kehidupan. Sehingga kita sebagai pemeran di atas panggung pentas harus dapat tampil menawan dihadapan penonton (masyarakat) dan Sutradara (Tuhan Yang Maha Esa ).

Selanjutnya, bina satuan dijelaskan bahwasannya pramuka penegak dan pandega dapat menjadi instruktur bagi adek-adek siaga dan penggalang. Secara lingkup kecil adalah meranah pada pendidikan di bawah penegak dan pandega, akan tetapi sebagai suatu proses pendewasaan secara kontekstual bidang satuan adalah miniatur kita dalam menjaga dan memanajemen sebuah kelompok sehingga kelompok tersebut dapat mencapai tujuan yang baik. Misalnya adalah cara kita bekerja dengan orang lain secara team work ini dapat terlaksana baik dan mumpuni ketika telah dapat memaksimalkan bina satuan. Jadi, bina satuan tidak meranah diri pribadi baik, akan tetapi bagaimana satu kelompok itu baik.

Bina ketiga adalah bina masyarakat, ini berobyek pada bagaimana kita nantinya akan bersikap di tengah-tengah masyarakat. Bentuk kegiatan pramuka penegak dan pandega yang berprinsip dari, oleh dan untuk pramuka penegak dan pandega dengan tanggung jawab pembina mengajarkan agar hidup mandiri dan siap mengontrol masyarakat ketika telah terjun di kalangan masyarakat secara luas. Hal inilah karakter kepemimpinan akan terbentuk yang dimulai dari bina satuan dan bina masyarakat. Pembelajaran kegiatan yang mempraktikan kerja bakti pada masyarakat serta mencitrakan kebaikan merupakan output dari bina masyarakat dan diharapkan penegak dan pandega berorientasi pada kerja bakti yang terarah serta berskala besar.

Dengan demikian maksud dan tujuan pemebentukan Dewan Kerja adalah memberi kesempatan kepada para Pramuka Penegak dan Pramuka Pandega untuk menambah pengetahuan dan pengalaman dibidang organisasi serta mengembangkan bakat kepemimpinan. Sedangkan untuk tujuan dewan kerja dibentuk adalah memberi kesempatan kepada pramuka penegak dan pramuka pandega untuk menambah pengetahuan, ketrampilan, dan pengalaman dalam pengelolaan organisasi, pengembangan bakat kepemimpinan dalam rangka upaya pengembangan pribadi dan pengabdiannya kepada Gerakan Pramuka, masyarakat, bangsa dan negera (SK 005 Tahun 2017).

Melalui Dewan Kerja pramuka penegak dan pramuka pandega mulai mengaplikasikan secara bersamaan hasil tri bina yang diajarkan pada gugus depan. Lingkup kepemimpinan Dewan Kerja pramuka penegak dan pandega diajarkan bagaimana mengelola dan memanajamen pramuka penegak dan pramuka pandega di wilayahnya masing-masing. Mengontrol dan menata dengan lingkup yang besar maka tenu diperlukan ketrampilan dalam hal pelayanan kepada orang lain. Hal inilah yang tentunya telah diajarkan dalam gerakan pramuka di dewan kerja pramuka penegak dan pramuka pandega.

Menurut PP Dewan Kerja 2017 pada Bab 4 Fungsi dan Tugas Pokok Dewan Kerja adalah sebagai berikut:

a. Fungsi

1) Pelaksana hasil musyawarah dan sidpar yang telah disetujui oleh kwartirnya

2) Memberikan nasehat kepada Kwartir tentang pelaksanaan pramuka dan kegiatan anggota muda golongan penegak dan pandega. 
3) Pengelola program mentoring dan kegiatan pramuka golongan penegak dan pandega di Kwartir.

4) Penghubung dengan Kwartir antara pramuka golongan penegak dan pandega diwilayah kerja.

5) Pendukung terwujudnya tugastugas Kwartir.

b. Tugas Pokok:

1) Melaksanakan keputusan Musppanitra yang disetujui oleh Majelis Kwartir (Muscab).

2) Memberikan bimbingan kepada Dewan Kerja tingkat di bawahnya.

3) Melaksanakan koordinasi dan konsultasi antar Dewan Kerja

4) Menevaluasi, mengkoordinasikan dan mengusulkan berbagai bentuk rencana dan kegiatan pembinaan, serta melaksanakan pengaturan bagi pramuka golongan penegak dan pandega ke Kwartir.

5) Meneliti dan mengevaluasi pelaksanaan pramuka dan rencana kegiatan Pramuka golongan Penegak Pandega, termasuk masalah-masalah yang dihadapi dalam proses pembinaan.

6) Melakukan promosi regulasi terkait pedoman pelaksanaan, terutama yang terkait dengan pramuka golongan penegak pandega.

7) Menyusun rencana dan laporan kegiatan yang dilaksanakan yang selanjutnya disampaikan pada sidpar (sidang paripurna)

8) Membantu kwartir mejalankan program

9) Menyelenggarakan sidang paripurna di tingkat kwartir

10) Menyelanggarakan Musppanitra ditingkat kwartir.

Fungsi dan tugas pokok seorang dewan kerja yang sangat kompleks tersebut telah menunjukan pembentukan pola pikir dan pendewasan bagi peserta didik pramuka penegak dan pramuka pandega. Dinamika yang terjadi di dewan kerja menuju sasaran yang diinginkan perlu adanya manajamen waktu dan pengorganisasian yang baik. Status seorang penegak dan pandega masih seorang pelajar atau mahasiswa maka tentunya hal ini perlu pembagian antara tugas dewan kerja dengan tugas wajib sekolah maupun kuliah. Disinilah, anggota dewan kerja melakukan pendewasaan yang nyata. Sedangkan program kerja, rencana kerja dan rencana stategi dewan kerja bagi pramuka penegak dan pramuka pendega sangatlah komplek maka tentunya dewan kerja benar-benar dilatih sebagai pelayan rekan-rekan sesama pramuka penegak dan pramuka pandega sebagai wujud pelaksanaan amanah. Hal ini merupakan pembentukan karakter kepemimpinan yang sulit didapatkan di organisasai lainnya.

Sisi lain dewan kerja adalah bagian integral kwartir, membuat dewan kerja juga bertanggung jawab untuk membantu kegiatan kwartir agar terlaksana sukses. Hubungan dewan kerja dengan kwartir diibaratkan antara anak dengan ayah, sehingga ketika orang tua ada hajat maka sejatinya anak membantu, begitupun sebaliknya tentu orang tua akan membantu ketika anaknya sedang ada hajat. Proses seperti telah dapat membentuk karakter komunikasi dewan kerja bagaiman berkomunikasi dengan atasan sehingga kebermanfaatan ini dapat diaplikasikan ketika memiliki atasan saat bekerja maupun yang lainnya.

Masuk pada forum tertinggi dewan kerja dibagi menjadi 3 forum. Pertama, forum tertinggi utama yaitu Musyawarah pramuka penegak dan pramuka pandega putri putra disingkat Musppanitra yang dilaksnaakan selama 5 tahun sekali. Kedua, forum Sidang paripurna yang dilaksanakan setiap tahun setelah musppanitra sebagai forum pertanggungjawabn pelaksnaan dewan kerja selama satu tahun dan membahas pandangan kinerja satu tahun ke 
depan sesuai amanah di musppanitra. Ketig adalah forum rapat pleno dimana ini adalah kegiatan rutinitas dewan kerja sebagai wahan kontoling dan komunikasi semua anggota dalam pelaksanaan setiap bulannya. Disini nanti akan dibahas serbaserbi serta isu kontemporer yang harus segera disikapi dan diberikan soslusi. Ketiga forum tersebut bentuknya adalah musyawarah, sehingga memang dalam pelaksanaannya menghindari yang namnya voting. Tataran inilah yang menunnjukan jiwa pemimpin yang menyelesaikan masalah secara mufakat sehingga tidak ada yang dirugikan satu sama lain.

\section{Karakter Kepemimpinan Anggota Dewan Kerja Cabang Kudus}

Kwartir Cabang Kudus salah satu kwartir yang berada di Kwartir Daerah Jawa Tengah. Kwartir Cabang Kudus memiliki nomer kwarcab 19 dari 35 kwarcab di Jawa Tengah. Letak kudus di wilayah korwil pati, maka kwartir cabang Kudus masuk pada binaan Binwil Pati yang terdiri dari Pati, Jepara, Kudus, Rembang dan Blora.

Kwartir Cabang Kudus dalam pelaksanaan tugasnya memiliki badan kelengkapan yaitu Dewan Kerja Cabang Cabang Kudus. Dewan Kerja merupakan bagian integral yang berisikan Pramuka Penegak dan Pramuka Pandega sebagai pelaksana yang mengurusi kegiatan pramuka penegak dan pandega. Dinamika yang terjadi di Dewan Kerja Cabang Kudus memiliki keunikan dan keseruan dalam prosesnya.

Dewan Kerja Cabang Kudus melaksanakan setiap amanahnya sesuai dengan rencana kerja dan rencana strategi yang diamanahkan dari Musppanitra. Ahmad Kusaini, menuturkan bahwa rencana kerja dan rencana strategi merupakan sasaran capaian, sehingga berhasilnya kinerja dewan kerja terletak pada pencapaian rencana kerja dan rencan strategi. Hal ini juga senada dengan Dedik Sofyan seorang purna Ketua Dewan Kerja
Cabang Kudus bahwa patokan dalam beroganisasi di dewan kerja adalah rencana kerja dan rencana stategi yang telah diamanahkan kepada DKC dari Musppanitra.

Seorang dewan kerja bertanggung jawab atas semua ketidak capaian dan pencapaian setiap tahunnya kepada Dewan Kerja dibawahnya. Dalam hal ini, Dewan Kerja Cabang Kudus bertanggung jawab untuk melaporkan hasil capaian dan tidaknya terhadap Dewan Kerja Ranting di forum Sidang Paripurna yang dilaksanakan setiap tahunnya. Bentuk amanah dan tanggung jawab yang sangat kompleks sangatlah menyita banyak waktu dan pikiran sehingga seorang anggota dewan kerja harus cakap dan tanggap.

Alifia Nur Nianah salah satu anggota Dewan Kerja Cabang Kudus menuturkan bahwa dia menjadi anggota DKC Kudus semenjak 2014, dan mulai bergabung di DKC Kudus pola kehidupan berubah derastis. Alifia menuturkan bahwa posisi masuk DKC Kudus masih sebagai pelajar samapai masuk bangku perkuliahan DKC Kuduslah yang telah memberikan bekal kematangan berpfikir di bangku perkuliahan.

Ahmad Kusaini, sebagai Ketua Dewan Kerja Cabang menyampaikan sebagai anggota DKC Kudus memang tidak mudah, tapi disini tidak mencari orang yang pintar akan tetapi mencari orang yang mau belajar. Jadi, karena sifat kerja gerakan pramuka yang ikhlas bakti bina bangsa menjadikan tidak ada upah ataupun yang lainnya di dewan kerja. Sehingga, Ahmad Kusaini sebagai Ketua Dewan Kerja terus menyampikan prinsip berorganisasi di dewan kerja,

"Jangan berharap apa yang diberikan Dewan Kerja kepada kita, tapi apa yang dapat kita berikan kepada Dewan Kerja. Kita yang butuh Dewan Kerja, tidak Dewan Kerja yang butuh kita".

Maksudnya adalah, sejatinya sebagai dewan kerja tekad bulat sebagai jalan 
mencari ilmu dan menerapkannya. Organisasi dewan kerja tidak memiliki profit oriented tapi hanya sosial oriented. Akan tetapi, dewan kerja cabang kudus inilah anggota dapat kenal dan mendapatkan relasi orang banyak setingkat cabang ke atas dan ke bawah yang dapat dijadikan bekal masa depan nantinya.

Alifia Nur Nianah sebagai anggota juga menyatakan hal yang sama seperti penyampaian Ketua DKC Kudus. Dia juga menyampaikan bahwasannya di DKC Kudus tidak hanya melaksanakan tugas yang sesuai di PP Dewan Kerja Tahun 2017, DKC Kudus juga memiliki misi besar sebagai anak kwartir untuk membantu kegiatan Kwartir dan tidak hanya itu sebagai anak Kwartir kita juga diberikan tanggung jawab atas terjaganya Sanggar Bakti Kwartir Cabang Kudus yang menjadi pusat kegiatan kepramukaan di kudus.

“... Jadi pengalaman di dewan kerja tidak hanya sebagai organisatoris, akan tetapi di DKC Kudus ini tau makna ikhlas yang sebenarnya tanpa mengharapkan imbalan apapun" tutur Alifia Nur Nianah.

Dedik Sofyan juga berpesan, bahwa memang dewan kerja tidak ada imbalan apa-apa. Tapi lakukanlah yang terbaik karena sejatinya teman-teman DKC dapat kenal dengan pejabat setingkat cabang yang nanti masa depan membutuhkan temanteman sudah ada pengalaman. Hal profit tidaklah masalah, masalah ketika renja

\section{Simpulan}

Pola pembinaan pramuka penegak dan pramuka pandega kwartir cabang kudus menganut pada Surat Keputusan Kwatir Nasional Nomor 176 Tahun 2013 tentang Pola Mekanisme Pembinaan Pramuka Penegak dan Pramuka Pandega. Prinsip Pembinaannya adalah Tribina, bina diri, bina satuan dan bina masyarakat. Selanjutnya wadah pembentukan karakter terdapat di tiga wadah pembinaan yaitu Gugus Depan, Satuan Karya Pramuka dan Kwartir yaitu sebagi Dewan Kerja. renstra tidak tercapai dan ketika kegiatan giat prestasi ada yang komplain, tutrnya.

Dengan demikian, secara dinamika Dewan Kerja Cabang Kudus telah melaksnakan Tugas Pokok dan Fungsi sebagai dewan kerja dengan baik. Beberapa ornamen dinamika yang diluar Tupoksi memberikan penjelas bahwa DKC Kudus bergerak pada bidang Gerakan Pramuka yang berpedoman pada Ikhlas bakti bina bangsa. Sehingga segala bentuk profit tidak dipermaslahkan yang penting dapat melakukan organisasi secara maksimal.

Karakter kepemimpinan anggota DKC Kudus dapat dilihat dari sepak terjang dalam menghandel Pramuka Penegak dan Pramuka Pandega se Kwartir Cabang Kudus. Tidak hanya itu, seni komunikasi telah dipunyai bagi anggota DKC Kudus karena seringnya kordinasi dan konsultasi terhadap anggota dewasa di Kwartir Cabag Kudus dalam hal ini Andalan Kwartir dan Pimpinan. Ditambah lagi rasa tanggung jawabnya DKC Kudus dapat disimpulkan bahwa karakter secara sikap telah terbentuk. Penyelesaian masalah setingkat cabang yang telah ditanggungjawabkan kepada anggota pramuka penegak dan pandega yang beranggota di DKC Kudus menjadikan pembuka cakrawala manusia dan telah menghantarkan pada bentuk pendewasaan rekan-rekan pemuda yang ada di Dewan Kerja.

Pembentukan karakter pramuka penegak dan pandega terletak pada tiga wadah pembinaan yaitu Gugus Depan, Satuan Karya Pramuka dan Kwartir yaitu Dewan Kerja. Fokus penelitian ini pada Wadah Pembinaan di Kwartir yaitu Dewan Kerja dimana Dewan Kerja merupakan badan kelengkapan kwartir yang tidak dapat dipisahkan. Sifat organisasinya adalah kolektif kolegial jadi semua keputusan diambil secara musyawarah. Forum tertinggi Dewan Kerja ada tiga yaitu Musppanitra yang dilaksanakan setiap 5 tahun sekali, Sidang Paripurna yang dilaksanakan 
setiap 1 tahun sekali dan yang terakhir adalah Rapat pleno sebagai rutinitas dewan kerja paling sedikit 6 kali dalam satu tahun.

Karakter kepemimpinan anggota DKC Kudus dapat dilihat dari sepak terjang dalam mengkoordinir Pramuka Penegak dan Pramuka Pandega se Kwartir Cabang Kudus. Tidak hanya itu, seni komunikasi telah dipunyai bagi anggota DKC Kudus karena seringnya kordinasi dan konsultasi terhadap anggota dewasa di Kwartir Cabag Kudus dalam hal ini Andalan Kwartir dan Pimpinan. Ditambahnya pernak pernik tanggung jawabnya DKC Kudus dapat disimpulkan bahwa karakter secara sikap telah terbentuk. Penyelesaian masalah setingkat cabang yang telah ditanggungjawabkan kepada anggota pramuka penegak dan pandega yang beranggota di DKC Kudus menjadikan pembuka cakrawala manusia dan telah menghantarkan pada bentuk pendewasaan rekan-rekan pemuda yang ada di Dewan Kerja.

\section{Daftar Pustaka}

Arman. "Analisis Proses Pembinaan Kepramukaan Penegak Satuan Karya Wirakartika Koramil 07 Johan Pahawan Kodim 0105 Aceh Barat”. Skripsi. Universitas Teuku Umar. 2014.

Chomaidi dan Salamah. Pendidikan dan Pengajaran Strategi Pembelajaran Sekolah. Jakarta : PT Grasindo, 2018.

Ningsih, Sri Wahyu. "Pengaruh Kegiatan Ekstrakurikuler Pramuka Terhadap Karakter Peserta Didik Di Mi Laikang Kecamatan Ma'rang Kabupaten Pangkep". AULADUNA: Jurnal Pendidikan Dasar Islam Vol 4, No 1 (2017).

Sumanta, M. dan Fitri Juwita Santi, Seri Lulus SKU Pramuka Penggealang Ramu. Jakarta : Erlangga, 2014.
Surat Keputusan Kwartir Nasional 176 tahun 2013 tentang Pola Mekanisme Pembinaan Pramuka Penegak dan Pramuka Pandega.

Surat Keputusan Kwartir Nasional Nomor 005 tahun 2017 tentang Petunjuk Penyelenggaraan Pramuka Penegak dan Pramuka Pandega.

Surat Keputusan Kwartir Nasional Nomor 170.A tentang Petunjuk Penyelanggaraan Satuan Karya Pramuka

Undang-Undang Nomor 12 Tahun 2010 tentang Gerakan Pramuka.

Wikipedia.com. (2020, 17 Februari). Daftar Sekolah Dasar Negeri di Indonesia. diakses pada tanggal 17 Februari 2020.https://id.wikipedia.org/wiki/Dafta r_sekolah_dasar_negeri_di_Indonesia. 